\title{
Influence of Chinese National Centralized Drug Procurement on the price of policy-related drugs: an interrupted time series analysis
}

\author{
Ni Wang ${ }^{1,+}$, Ying Yang ${ }^{1,2, *,+}$, Luxinyi Xu ${ }^{1}$, Zongfu Mao ${ }^{1,2}$, Dan Cui ${ }^{1,2, *}$ \\ 1 School of Health Sciences, Wuhan University, 115\# Donghu Road, Wuhan 430071, China; \\ 2018203050035@whu.edu.cn (N.W.); yangying@whu.edu.cn (Y.Y.); 2020203050034@whu.edu.cn (L.X.); \\ zfmao@whu.edu.cn (Z.M.); alyssazz@126.com (D.C.) \\ 2 Global Health Institute, Wuhan University, 115\# Donghu Road, Wuhan 430071, China \\ * Correspondence: yangying@whu.edu.cn (Y.Y.); alyssazz@126.com (D.C.); Tel.: +86-156-2326-3020 (Y.Y.); \\ +86-133-1715-0755 (D.C.) \\ + These authors contributed equally to this work.
}

\begin{abstract}
In 2019, Chinese government implemented the first round of National Centralized Drug Procurement (NCDP) pilot (so-called "4+7" policy) in mainland China, achieved a prominent price reduction of $52 \%$ on average for 25 bidding winning products. Under cross-price elasticity theory, the price behavior of pharmaceutical enterprises for policy-related drugs might change. This study used drug purchasing data from the Centralized Drug Procurement Survey in Shenzhen 2019, and applied single-group Interruption Time Series (ITS) design to examine the impact of "4+7" policy on the drug price index (DPI) of policy-related drugs. The ITS analysis showed that the DPI of winning $(-0.183$ per month, $p<0.0001)$ and non-winning $(-0.034$ per month, $p=0.046)$ products significantly decreased after the implementation of " $4+7$ " policy. No significant difference was found for the immediate change of DPI for alternative drugs $(p=0.537)$, while a significant decrease in change trend was detected in the post-" $4+7 "$ policy period $(-0.003$ per month, $p=0.014)$. The DPI of the overall policy-related drugs significantly decreased $(-0.261$ per month, $p<0.0001)$ after " $4+7$ " policy. These findings indicate that the price behavior of pharmaceutical enterprises changed under NCDP policy, while the price linkage effect is still limited. It is necessary to further expand the scope of centralized purchased drugs and strengthen the monitoring of related drugs regarding price change and consumption structure.
\end{abstract}

Keywords: National Centralized Drug Procurement; "4+7" policy; drug price; interrupted time series; volume-based procurement.

\section{Introduction}

Worldwide, many countries are facing the challenge of ever-increasing pharmaceutical expenditures [1,2], and the global pharmaceutical market reached $\$ 955$ billion in 2019 [3]. In China, the total health expenditure increased from 145.4 billion yuan in 2008 to 5799.8 billion yuan in 2018, with an average compound annual growth rate of $13.4 \%$ [4]. In 2018, the total pharmaceutical expenditure was 1914.89 billion yuan in China, accounting for $32.39 \%$ of the total health expenditure [5], which was much higher than the average level of $17 \%$ in the Organization for Economic Co-operation and Development (OECD) countries [6].

It is common practice worldwide that lowering drug prices and reducing drug expenditures by volume-based drug procurement $[7,8]$. Since 2000, the Chinese government has carried out drug centralized procurement, and gradually formed the centralized procurement model at the provincial level $[9,10]$. In January 2019, the General Office 
of the State Council of the People's Republic of China implemented the National Centralized Drug Procurement (NCDP) policy [11]. In the first round of the NCDP pilot, four municipalities and seven sub-provincial cities in mainland China were selected as pilot cities, thus, the first round of NCDP pilot is also known as " $4+7$ " policy. Under NCDP policy, original branded drugs and generic drugs that passed the consistency evaluation of quality and efficacy were involved to conduct volume-based procurement, leading to a decline in drug prices by "group purchase" [12]. In the " $4+7$ " policy, 25 drugs were centralized purchased $(\mathrm{CP})$ with an average price decline of $52 \%$ [13].

According to the cross-price elasticity theory, in a group of drugs with substitution relationship, the percentage change in quantity demanded for one product in response to a percentage change in price of another product [14,15]. Under the NCDP policy, the price behavior of pharmaceutical enterprises related to $\mathrm{CP}$ drugs would inevitably change. Previous studies reported the change of policy-related drugs after the implementation of " $4+7$ " policy. Wang et al.'s [16] study in Shanghai found that the average daily cost of branded and generic cardiovascular drugs fell by $66.45 \%$ and $24.24 \%$ after the implementation of " $4+7$ " policy. Chen et al. [17] reported that the price of winning products, non-winning products and basic alternative drugs decreased in Shenzhen. Yang et al. [18] indicated that the price of non-winning antipsychotic drugs decreased by more than $10 \%$ as the results of " $4+7$ " policy, while the price of non-winning drugs in the same varieties dropped by less than $5 \%$. However, Ye et al. [19] reported opposite results that the defined daily dose cost (DDDc) of non-winning products and alternative drugs increased by $17.43 \%$ and $7.68 \%$, respectively.

In summary, previous findings regarding the impact of NCDP policy on drug prices have been controversial. In the present study, we took the " $4+7$ " policy as an example, using Drug Price Index (DPI) and single-group Interruption Time Series (ITS) to examine the impact of the NCDP policy on the change of policy-related drug prices in Shenzhen.

\section{Materials and Methods}

\subsection{Data Sources}

This study used data from the Centralized Drug Procurement Survey in Shenzhen 2019 (CDPS-SZ 2019) [17]. In China, the CDPS-SZ 2019 was organized and conducted by the Global Health Institute of Wuhan University between December 2019 and January 2020. The survey aimed to evaluate the effect of drug-related policies in Shenzhen, China, and collected monthly drug purchase order data between 2018 and 2019. In the CDPS-SZ 2019 database, each purchase order record included purchase date, generic name, dosage form, specification, pharmaceutical manufacturer, price per unit, purchase volume, purchase expenditures, etc. A general database containing 963,127 monthly aggregated purchase order records was established, involving 1079 drug varieties (by generic name), 346 medical institutions, 857 pharmaceutical manufacturers. The total purchase expenditures reached RMB 20.87 billion.

The purpose of this study is to examine the impact of NCDP policy on prices of policy-related drugs. Thus, we included samples with the following criteria: (a) the medication covered by " $4+7$ " CP and their alternative drugs (Table A1). The CP drugs were sorted into winning and non-winning products based on the bidding results of "4+7" policy; (b) the time period between January 2018 and December 2019; and (c) the medical institutions purchasing drugs were from Shenzhen, China. Finally, 47,163 purchase order records of 82 drug varieties (by generic name) were included in the analysis. Figure 1 presents the flow chart of sample screening. 


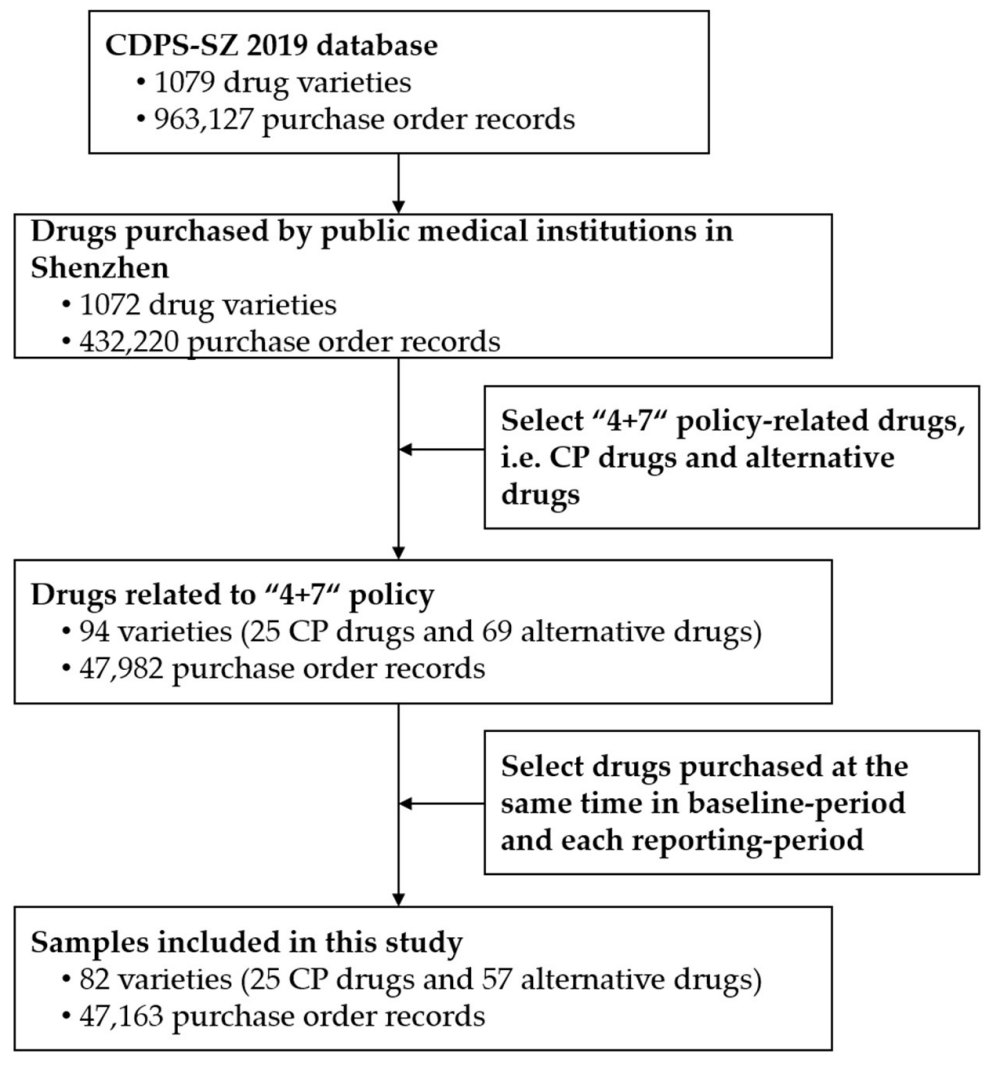

Figure 1. Flow chart of sample screening. Note: $\mathrm{CP}$, centralized purchased.

\subsection{Outcome Variables}

Drug Price Index was used as outcome variable in this study, which is a common indicator reflecting the trend of drug price change over different periods [20, 21]. This study applied three commonly used DPI: Laspeyres Price Index $(L P)$, Paasche Price Index $\left(P_{P}\right)$, and Fisher Price Index $\left(F_{P}\right)$.

$L P$ is calculated as the ratio of price in reporting period and the price in baseline period, weighted by the quantity in baseline period. This method assumes that the consumption structure of drugs remains unchanged in different periods, and is applicable to reflect the pure price change of drugs. $L p$ is calculated as follows:

$$
L_{P}=\frac{\sum P_{1} Q_{0}}{\sum P_{0} Q_{0}}
$$

$P_{P}$ is calculated as the ratio of price in reporting period and the price in base-period, weighted by the quantity in reporting period. The index reflects the increase or decrease in drug costs due to the price change when the quantity and consumption structure has changed. $P_{P}$ is calculated as follows:

$$
P_{P}=\frac{\sum P_{1} Q_{1}}{\sum P_{0} Q_{1}}
$$

$F_{P}$ is calculated as the geometric mean of $L_{P}$ and $P_{P}$, which was weighted by the quantity in both baseline period and reporting period. Thus, $F_{P}$ can equalize and average the biases of $L p$ and $P_{P}$. Theoretical researches showed that $F_{P}$ is an optimal form of price index, and is called "the ideal index" [22]. $F_{P}$ is calculated as follows:

$$
F_{P}=\sqrt{L_{P} \times P_{P}}
$$

In the above formula (1)-(3), $\mathrm{P}$ means the price, $\mathrm{P}_{0}$ and $\mathrm{P}_{1}$ refer to price per Defined Daily Doses (DDDs) of each product in baseline- and reporting period. Q means pur- 
chasing quantity, $\mathrm{Q}_{0}$ and $\mathrm{Q}_{1}$ refer to DDDs of each product in baseline- and reporting period. DDDs is the ratio of the quantity of drug utilization and Defined Daily Dose (DDD) [23]. If the drug price index $>1$, it indicates the increase of drug price in the reporting period when compared with the base-period; If the drug price index $=1$, it means that drug prices remain unchanged over the two periods; If the drug price index $<1$, it means that drug prices in the reporting period decrease compared with the base period.

In this study, January to June 2018 was assigned as the baseline period, and July 2018 to December 2019 was assigned as the reporting periods to calculate drug price indexes of each month (18 months).

\subsection{Statistical Analysis}

Descriptive statistics were used. We first described the change of DPI of included drugs before (July 2018 to February 2019) and after (March to December 2019) the implementation of " $4+7$ " policy.

Interrupted time-series analysis was applied to assess the change of Fisher Price Index after the implementation of " $4+7$ " policy. ITS is a commonly used approach for evaluating changes in longitudinal series following a quasi-experimental intervention occurring at a fixed point in time. The interrupted time series was constructed with DPI data in Shenzhen from July 2018 to December 2019. The time unit was set to 1 month and the intervention time point was set to March 2019, making 18 time points available for analysis, including 8 points as pre-" $4+7$ " policy period and 10 points as post-" $4+7$ " policy period. To estimate the effect of the intervention on the outcome variables, the following segmented linear regression model was developed [24-26]:

$$
Y_{t}=\beta_{0}+\beta_{1} \times \text { time }+\beta_{2} \times \text { intervention }+\beta_{3} \times \text { time after intervention }+\varepsilon_{t}
$$

Where, $Y_{t}$ is the independent outcome variable (i.e. Fisher Price Index) in month $t$. time is a continuous variable indicating time in months at time $t$ from the start of the observation period. intervention is an indicator for time $t$ in the pre-" $4+7$ " policy period (intervention $=0$ ) and post-" $4+7$ " policy period (intervention $=1$ ). time after intervention is a continuous variable indicating months in the post-" $4+7$ " policy period (time in the pre-" $4+7 "$ policy period is coded 0 ).

In this model, $\beta_{0}$ estimates the baseline level of the independent variable at the beginning of the observation period. $\beta_{1}$ estimates the linear trend during the pre-intervention period. $\beta_{2}$ estimates the level change in the outcome variable immediately following the intervention. $\beta_{3}$ estimates the trend change in the outcome variable in the post-intervention period compared with the pre-intervention period. $\varepsilon_{t}$ is an estimate of the random error at time $t$. Durbin-Watson test was performed to test the presence of first-order auto-correlation (a value around 2 indicates no sign of auto-correlation). If autocorrelation is detected, the Prais-Winsten method was applied to estimate the regression. Stata version 16.0 was used to perform the ITS analysis. A $p$-value $<0.05$ was considered statistically significant.

\section{Results}

\subsection{Descriptive analysis}

Descriptive analysis was conducted to compare the change of $L_{P}, P_{P}$, and $F_{P}$ in the pre- and post-" $4+7 "$ policy periods. Table 1 lists the results of winning and non-winning products. After the implementation of " $4+7 "$ policy, the $L_{P}, P_{P}$, and $F_{P}$ of winning products decreased by $53.42 \%, 54.82 \%$, and $79.02 \%$, respectively. The $F_{P}$ of winning products declined from $0.44(S D=0.08)$ in pre-"4+7" policy period to $0.09(S D=0.01)$ in post-" $4+7 "$ policy period. The $L_{P}, P_{P}$, and $F_{P}$ of non-winning products decreased by $2.32 \%, 9.91 \%$, and $11.96 \%$, respectively. The $F_{P}$ of non-winning products declined from $0.49(S D=0.01)$ in pre-" $4+7$ " policy period to $0.43(S D=0.03)$ in post-" $4+7$ " policy period. 
Table 1. The change of drug price index for winning and non-winning products pre- and post-"4+7" policy.

\begin{tabular}{|c|c|c|c|c|c|c|c|c|c|}
\hline & \multicolumn{3}{|c|}{$L P$} & \multicolumn{3}{|c|}{$P_{P}$} & \multicolumn{3}{|c|}{$F_{P}$} \\
\hline & Pre- & Post- & GR (\%) & Pre- & Post- & GR (\%) & Pre- & Post- & GR $(\%)$ \\
\hline \multicolumn{10}{|c|}{ Winning products } \\
\hline Mean & 0.93 & 0.44 & -53.42 & 0.94 & 0.42 & -54.82 & 0.44 & 0.09 & -79.02 \\
\hline SD & 0.09 & 0.03 & - & 0.08 & 0.03 & - & 0.08 & 0.01 & - \\
\hline Min & 0.80 & 0.42 & - & 0.81 & 0.41 & - & 0.32 & 0.09 & - \\
\hline Max & 1.00 & 0.53 & - & 1.00 & 0.51 & - & 0.50 & 0.13 & - \\
\hline \multicolumn{10}{|c|}{ Non-winning products } \\
\hline Mean & 0.99 & 0.96 & -2.32 & 0.99 & 0.89 & -9.91 & 0.49 & 0.43 & -11.96 \\
\hline SD & 0.01 & 0.02 & - & 0.01 & 0.04 & - & 0.01 & 0.03 & - \\
\hline Min & 0.97 & 0.94 & - & 0.97 & 0.85 & - & 0.47 & 0.41 & - \\
\hline Max & 1.00 & 1.00 & - & 1.00 & 1.00 & - & 0.50 & 0.50 & - \\
\hline
\end{tabular}

Note: LP: Laspeyres Price Index; $P_{P}$ : Paasche Price Index; $F_{P}$ : Fisher Price Index; Pre-: pre-"4+7" policy, i.e. July 2018 to February 2019; Post-: post-"4+7" policy, i.e. March 2019 to December 2019; GR: growth rate; SD: standard deviation.

Table 2 summarizes the results of $\mathrm{CP}$ drugs and alternative drugs. After the implementation of " $4+7$ " policy, the $L P, P_{P}$, and $F P$ of CP drugs decreased by $58.95 \%, 60.68 \%$, and $83.38 \%$, respectively. The $F_{P}$ of CP drugs dropped from $0.48(S D=0.02)$ in pre-" $4+7 "$ policy period to $0.08(S D=0.03)$ in post-" $4+7 "$ policy period. The $L_{P}, P_{P}$, and $F_{P}$ of alternative drugs decreased by $2.30 \%, 2.11 \%$, and $4.34 \%$, respectively. The $F_{P}$ of alternative drugs dropped from $0.49(S D=0.01)$ in pre-"4+7" policy period to $0.47(S D=0.02)$ in post-" $4+7 "$ policy period. For the overall of $C P$ drugs and alternative drugs, the $L_{P}, P_{P}$, and $F_{P}$ decreased by $35.83 \%, 41.49 \%$, and $62.21 \%$, respectively. The $F_{P}$ of the overall drugs dropped from $0.48(S D=0.01)$ in pre-" $4+7 "$ policy period to $0.18(S D=0.03)$ in post-" $4+7$ " policy period.

Table 2. The change of drug price index for centralized purchased drugs and alternative drugs preand post-" $4+7 "$ policy.

\begin{tabular}{|c|c|c|c|c|c|c|c|c|c|}
\hline & \multicolumn{3}{|c|}{$L p$} & \multicolumn{3}{|c|}{$P_{P}$} & \multicolumn{3}{|c|}{$F_{P}$} \\
\hline & Pre- & Post- & GR (\%) & Pre- & Post- & GR (\%) & Pre- & Post- & GR (\%) \\
\hline \multicolumn{10}{|c|}{ CP drugs } \\
\hline Mean & 0.98 & 0.40 & -58.95 & 0.98 & 0.39 & -60.68 & 0.48 & 0.08 & -83.38 \\
\hline SD & 0.02 & 0.07 & - & 0.01 & 0.07 & - & 0.02 & 0.03 & - \\
\hline Min & 0.95 & 0.35 & - & 0.96 & 0.34 & - & 0.46 & 0.06 & - \\
\hline Max & 1.00 & 0.60 & - & 0.99 & 0.59 & - & 0.50 & 0.18 & . \\
\hline \multicolumn{10}{|c|}{ Alternatives } \\
\hline Mean & 0.99 & 0.97 & -2.30 & 0.99 & 0.97 & -2.11 & 0.49 & 0.47 & -4.34 \\
\hline SD & 0.01 & 0.02 & - & 0.01 & 0.02 & - & 0.01 & 0.02 & - \\
\hline Min & 0.98 & 0.95 & - & 0.97 & 0.95 & - & 0.48 & 0.45 & - \\
\hline Max & 1.02 & 1.00 & - & 1.00 & 1.00 & - & 0.51 & 0.50 & . \\
\hline \multicolumn{10}{|l|}{ Overall } \\
\hline Mean & 0.98 & 0.63 & -35.83 & 0.98 & 0.58 & -41.49 & 0.48 & 0.18 & -62.21 \\
\hline SD & 0.01 & 0.05 & - & 0.01 & 0.06 & - & 0.01 & 0.03 & - \\
\hline Min & 0.97 & 0.60 & - & 0.97 & 0.52 & - & 0.47 & 0.16 & 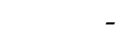 \\
\hline Max & 1.00 & 0.77 & - & 1.00 & 0.72 & - & 0.50 & 0.28 & - \\
\hline
\end{tabular}

Note: $L P$, Laspeyres Price Index; $P_{P}$, Paasche Price Index; $F P$, Fisher Price Index; Pre-, pre-"4+7" policy, i.e. July 2018 to February 2019; Post-, post-"4+7" policy, i.e. March 2019 to December 2019; GR, growth rate; $\mathrm{CP}$, centralized purchased; $\mathrm{SD}$, standard deviation.

\subsection{ITS analysis}

3.2.1. Winning and non-winning products 
The ITS results of winning and non-winning products are presented in Table 3 . The $F_{P}$ of winning products significantly declined (-0.183 per month, $95 \% C I=-0.248$ to -0.118 , $p$-value $<0.001)$ in the start of the " $4+7$ " policy implementation, while significant increment $(0.024$ per month, $95 \% C I=0.008$ to $0.041, p$-value $=0.007)$ in $F$ of winning products was found between the pre- and post-" $4+7$ " policy slopes. In the start of the " $4+7$ " policy implementation, significant decrease ( -0.034 per month, $95 \% C I=-0.067$ to -0.001 , $p$-value $=0.046$ ) was found in $F_{P}$ of non-winning products. However, the change in the pre- and post-" $4+7$ " policy slopes had no significant difference $(p$-value $=0.262)$ (Figure 2$)$.

Table 3. ITS results of Fisher Price Index for winning and non-winning products.

\begin{tabular}{lrrrrrrr}
\hline & Coef. & S.E & $t$ & $p$-value & \multicolumn{2}{c}{$95 \% C I$} \\
\cline { 6 - 7 } & & & & & & & \\
& & & & & & & \\
Winning products & & & & & & \\
Baseline level, $\beta_{0}$ & -0.029 & 0.006 & -5.240 & 0.000 & -0.041 & -0.017 \\
Baseline trend, $\beta_{1}$ & -0.183 & 0.030 & -6.050 & 0.000 & -0.248 & -0.118 \\
Level change, $\beta_{2}$ & 0.024 & 0.008 & 3.190 & 0.007 & 0.008 & 0.041 \\
Trend change, $\beta_{3}$ & & & & & & \\
Non-winning products & 0.491 & 0.010 & 49.150 & 0.000 & 0.470 & 0.513 \\
Baseline level, $\beta_{0}$ & -0.001 & 0.002 & -0.500 & 0.628 & -0.006 & 0.004 \\
Baseline trend, $\beta_{1}$ & -0.034 & 0.015 & -2.190 & 0.046 & -0.067 & -0.001 \\
Level change, $\beta_{2}$ & -0.003 & 0.003 & -1.170 & 0.262 & -0.010 & 0.003 \\
Trend change, $\beta_{3}$ & & & & & & \\
\hline
\end{tabular}

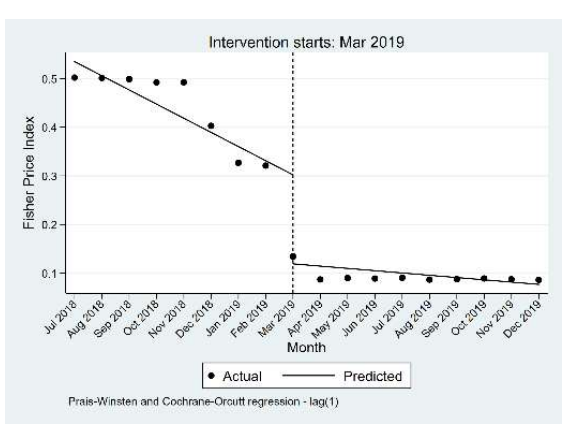

(a)

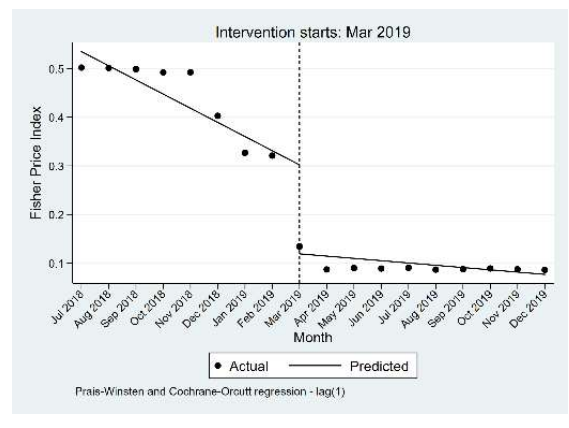

(b)

Figure 2. The Fisher Price Index of winning and non-winning products in the pre- and post-"4+7" policy periods. (a) winning products, (b) non-winning products.

\subsection{2. $\mathrm{CP}$ and alternative drugs}

The ITS results of CP drugs and alternative drugs are presented in Table 4. The $F_{P}$ of CP drugs significantly declined (-0.347 per month, 95\% CI $=-0.395$ to -0.299 , $p$-value < 0.001 ) in the start of the " $4+7$ " policy implementation. However, no statistically significant difference was found in the trend change between the pre- and post-" $4+7$ " policy periods $(p$-value $=0.761)$. Significant decline $(-0.003$ per month, $95 \% C I=-0.006$ to $-0.001, p$-value $=$ $0.014)$ in $F_{P}$ of alternative drugs was found between the pre- and post-"4+7" policy slopes. For the overall of CP drugs and alternative drugs, the FP significantly decreased (-0.261 per month, $95 \% C I=-0.298$ to $-0.223, p$-value $<0.001)$ at the start of the " $4+7$ " policy implementation, while the change in the pre- and post-" $4+7$ " policy slopes had no significant difference $(p$-value $=0.268)$ (Figure 3$)$.

Table 4. ITS results of Fisher Price Index for centralized purchased drugs and alternative drugs.

\begin{tabular}{cccccc}
\hline \multirow{2}{*}{ Item } & Coef. & S.E & $t$ & $p$-value & \multicolumn{2}{c}{$95 \% C I$} \\
\cline { 4 - 5 } & & &
\end{tabular}

CP drugs 


\begin{tabular}{lrrrrrr} 
Baseline level, $\beta_{0}$ & 0.498 & 0.015 & 33.670 & 0.000 & 0.466 & 0.530 \\
Baseline trend, $\beta_{1}$ & -0.005 & 0.004 & -1.470 & 0.164 & -0.013 & 0.002 \\
Level change, $\beta_{2}$ & -0.347 & 0.022 & -15.480 & 0.000 & -0.395 & -0.299 \\
Trend change, $\beta_{3}$ & -0.001 & 0.004 & -0.310 & 0.761 & -0.011 & 0.008 \\
Alternatives & & & & & & \\
Baseline level, $\beta_{0}$ & 0.494 & 0.004 & 115.580 & 0.000 & 0.485 & 0.503 \\
Baseline trend, $\beta_{1}$ & -0.001 & 0.001 & -1.270 & 0.225 & -0.004 & 0.001 \\
Level change, $\beta_{2}$ & 0.004 & 0.007 & 0.630 & 0.537 & -0.010 & 0.018 \\
Trend change, $\beta_{3}$ & -0.003 & 0.001 & -2.790 & 0.014 & -0.006 & -0.001 \\
Overall & & & & & & \\
Baseline level, $\beta_{0}$ & 0.495 & 0.011 & 44.240 & 0.000 & 0.471 & 0.519 \\
Baseline trend, $\beta_{1}$ & -0.003 & 0.003 & -1.070 & 0.303 & -0.009 & 0.003 \\
Level change, $\beta_{2}$ & -0.261 & 0.017 & -15.020 & 0.000 & -0.298 & -0.223 \\
Trend change, $\beta_{3}$ & -0.004 & 0.003 & -1.150 & 0.268 & -0.011 & 0.003 \\
\hline
\end{tabular}

Note: $\mathrm{CP}$, centralized purchased.

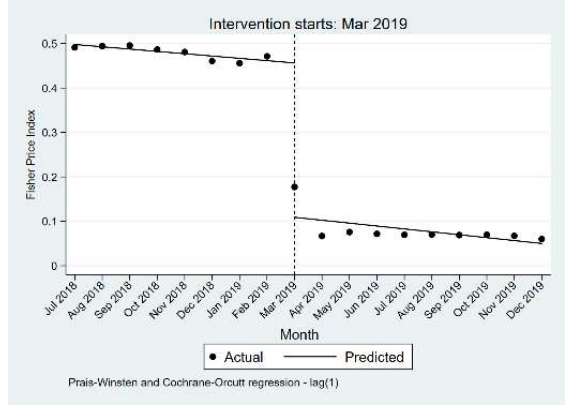

(a)

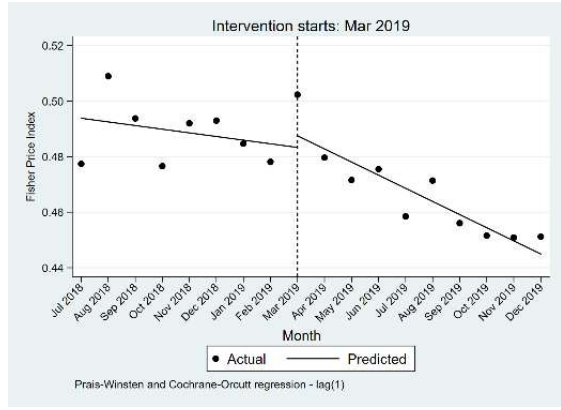

(b)

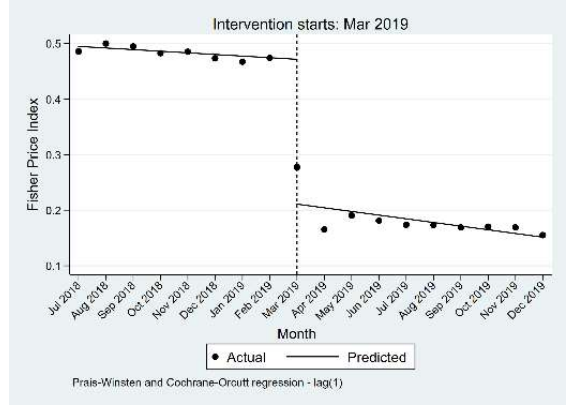

(c)

Figure 3. The Fisher Price Index of CP drugs and alternative drugs in the pre- and post-"4+7" policy periods. (a) CP drugs, (b) alternative drugs, (c) overall. Note: $\mathrm{CP}$, centralized purchased.

\section{Discussion}

This study aims to analyze the impact of NCDP on the prices of policy-related drugs. Overall, we found that the price of winning products decreased markedly and the prices of non-winning products dropped slightly after the implementation of " $4+7$ " policy, while the price change of alternative products had no statistical difference. For the overall drugs of $\mathrm{CP}$ and alternative, the comprehensive effect of " $4+7$ " policy on price reduction was significant, but the long-term effect of the policy was not obvious.

In the NCDP policy, $60 \%-70 \%$ of the market in pilot cities was assigned to conduct volume-based procurement, so as to relieve the artificially high drug prices by "group purchase" [27]. In this study, a notably direct effect of price reduction for winning products was observed, the $F P$ decreased by $79.02 \%$ and showed significant difference between the pre- and post-" $4+7$ " policy periods. Tan et al. [28] reported similar results that 25 winning drugs dropped by $51.88 \%$ in Guangzhou when compared with the 
pre-intervention period, among which the price of atorvaststin (10 $\mathrm{mg}^{*} 7$ tablets) dropped by $85.7 \%$. " $4+7$ " winning products covered original branded drugs and generic drugs that had passed consistency evaluation of quality and efficacy, which had large clinical demand and quality assurance. Thus, the decline in drug prices might effectively alleviate the medication burden of patients.

According to the cross-price elasticity theory, in a group of drugs with substitution relationship, the percentage change in quantity demanded for one product in response to a percentage change in price of another product $[14,15]$. With the announcement of " $4+7$ " bid winning results, pharmaceutical enterprises related to winning products made adjustments in pricing strategy and sales model [29]. It is reported that enterprises of non-winning products lowered the prices consciously to save the market [30]. In the present study, we found that the $F_{P}$ of non-winning products dropped by $11.96 \%$ after "4+7" policy in Shenzhen and showed statistically significant. Previous studies reported similar findings [18, 31]. Zhang \& Wang [31] found that the price of non-winning antihypertensive drugs showed a gradient decline, with the fall ranging from $1 \%$ to $52 \%$. Yang et al. [18] reported that the prices of three non-winning antidepressant drugs dropped by $12.67 \%$ on average. These findings indicated that the implementation of NCDP policy was conducive to improve market competitiveness and reshaping the competitive pattern of the pharmaceutical industry. However, ITS results of this study showed that there was no statistical difference in the changes of DPI slope of non-winning products between the pre- and post-" $4+7$ " policy periods, indicating that the price reduction of non-winning products might just be a temporary response of pharmaceutical enterprises during the implementation of policy.

In this study, the $F p$ of alternative products fell slightly by $4.34 \%$ in Shenzhen, while ITS analysis showed no statistical difference. Chen et al. [17] and Yang et al. [18] reported consistent results as this study. On the one hand, the price of alternative drugs did not change significantly (such as price increase) during the implementation of " $4+7$ " policy, indicating that the national monitoring did play an important role [32]. On the other hand, this study indicated that the effect of price reduction triggered by $25 \mathrm{CP}$ drugs was limited, and could not make a further impact on the market pattern. Furthermore, this study also found that the DPI slope of alternative products dropped markedly after the implementation of " $4+7$ " policy, indicating that the policy might help slow the growth of alternative drug prices and reduce the burden of patients.

Several potential limitations should be mentioned regarding the present study. Firstly, this study designed a single-group ITS by using the drug purchasing data in Shenzhen, and potential confounding factors other than NCDP might not be controlled, so there may be some bias in the results. Secondly, only one of the 11 pilot cities was included in the study (i.e. Shenzhen City), the results of this study may not fully represent the overall implementation effect of NCDP policy in China, caution should be exercised in generalizing the findings.

\section{Conclusions}

This study analyzed the impact of NCDP on the price of policy-related drugs in Shenzhen. The $F_{P}$ of 25 winning products notably decreased by $79.02 \%$. Under the NCDP policy, the market behavior of pharmaceutical enterprises of policy-related drugs changed. The $F_{P}$ of non-winning products dropped by $11.96 \%$ after the implementation of the policy, while the long-term trend of price reduction was not observed. In terms of alternative drugs, the price reduction at the start of the implementation of " $4+7$ " policy had no statistical difference. However, a trend of price growth slowing down for alternative drugs was observed in the post-" $4+7$ " policy period. In the future, on the one hand, it is necessary to expand the scope of CP drugs, so as to trigger the linkage effect of price reduction in a larger scope and to a greater extent. On the other hand, it is essential to strengthen the continuous monitoring of changes in the price and consumption structure of policy-related drugs, ensuring the accessibility and rationality of medications for patients. 
Author Contributions: Conceptualization, Y.Y. and D.C.; methodology, N.W. and Y.Y.; software, Y.Y.; formal analysis, N.W. and Y.Y.; investigation, N.W., Y.Y., L.X. and Z.M.; resources, Z.M. and D.C.; data curation, Y.Y. and Z.M.; writing-original draft preparation, N.W., Y.Y. and L.X.; writing-review and editing, N.W., Y.Y., L.X., Z.M. and D.C.; supervision, Z.M. and D.C.; project administration, D.C.; funding acquisition, Z.M. and D.C. All authors have read and agreed to the published version of the manuscript.

Funding: This work was supported by the Global Health Institute, Wuhan University, China. The role of the funding body included designing the study, the analysis and interpretation of data, and writing the manuscript.

Institutional Review Board Statement: Not applicable.

Informed Consent Statement: Not applicable.

Conflicts of Interest: The authors declare no conflict of interest.

\section{Appendix A}

Table A1. List of included drugs in this study.

\begin{tabular}{|c|l|}
\hline Drug Group & \multicolumn{1}{c|}{ Varieties } \\
\hline CP drugs & $\begin{array}{l}\text { irbesartan and hydrochlorothiazide, irbesartan, losartan, montmoril- } \\
\text { lonite, entecavir, cefuroxime, pemetrexed, atorvastatin, imatinib, } \\
\text { olanzapine, escitalopram, fosinopril, enalapril, montelukast, rosu- } \\
\text { vastatin, lisinopril, risperidone, paroxetine, gefitinib, levetiracetam, } \\
\text { clopidogrel, dexmedetomidine, tenofovir, amlodipine, flurbiprofen }\end{array}$ \\
\hline \multirow{3}{*}{ Alternative } & $\begin{array}{l}\text { adefovir, aspirin, oxcarbazepine, valproate, quetiapine, carbamaze- } \\
\text { pine, captopril, lamivudine, risperidone, nilotinib, nitrendipine, } \\
\text { drugs } \\
\text { cefprozil, cefaclor, cefixime, nifedipine, simvastatin, xuezhikang, ico- } \\
\text { tinib, cefuroxime, chlorpromazine, haloperidol, fluoxetine, penflu- } \\
\text { cefdinir, afatinib, telmisartan, fluvastatin, candesartan, perindopril, } \\
\text { sertraline, tiapride, lamotrigine, felodipine, aripiprazole, amlodipine } \\
\text { and atorvastatin, valsartan, ticagrelor, losartan potassium and hy- } \\
\text { drochlorothiazide, valsartan and amlodipine, perindopril and inda- } \\
\text { pamide }\end{array}$ \\
\hline
\end{tabular}

Note. CP, centralized purchased.

\section{References}

1. Parkinson, B.; Sermet, C.; Clement, F.; Crausaz, S.; Godman, B.; Garner, S.; Choudhury, M.; Pearson, SA.; Viney, R.; Lopert, R. et al. Disinvestment and Value-Based Purchasing Strategies for Pharmaceuticals: An International Review. Pharmacoeconomics 2015; 33:905-24. doi: 10.1007/s40273-015-0293-8.

2. Smith, C. Retail Prescription Drug Spending In The National Health Accounts. Health Affairs 2004; 23:160-7. doi: 10.1377/hlthaff.23.1.160.

3. The IQVIA Institute. Global Medicine Spending and Usage Trends Outlook to 2024; 2020. Available online: https://www.iqvia.com/insights/the-iqvia-institute/reports/global-medicine-spending-and-usage-trends (accessed on January 11, 2021).

4. National Health Commission. 2018 Statistical Bulletin of China's Health Development; 2020. Available online: http://www.gov.cn/guoqing/2020-04/29/content_5507528.htm (accessed on December 25, 2020).

5. Zhai, T.; Zhang, Y.; Wan, Q.; Chai, P.; Guo, F.; Li, Y.; Wang, R.; Chen, C.; Li, T.; Gao, R. The Results and Analysis of National Health Accounts in China in 2018. Chinese Health Economics 2020; 39:5-8. doi: 10.7664/CHE20200601.

6. National Health Development Research Center of the National Health Commission. 2018 China Total Health Expenditure Research Report. Beijing: Institute of health and economy press, 2018. 
7. Dylst, P.; Vulto, A.; Simoens, S. Tendering for outpatient prescription pharmaceuticals: what can be learned from current practices in Europe? Health Policy 2011; 101:146-52. doi: 10.1016/j.healthpol.2011.03.004.

8. Seidman, G.; Atun, R. Do changes to supply chains and procurement processes yield cost savings and improve availability of pharmaceuticals, vaccines or health products? A systematic review of evidence from low-income and middle-income countries. Bmj Glob Health 2017; 2:e243. doi: 10.1136/bmjgh-2016-000243.

9. Mao, Z.; Shen, X.; Wang, Q. Retrospective study on drug's centralized purchasing system of healthcare institutions in China. Chinese Journal of Health Policy 2014; 7:5-10. doi: 10.3969/j.issn.1674-2982.2014.10.002.

10. Zhang, R.; Qiao, J.; Mao, Z.; Cui, D. A Review on the Current Situation of Centralized Drug Procurement in China's Public Medical Institutions. Chinese Journal of Pharmacoepidemiology 2019; 28:199-204

11. General Office of the State Council of the People's Republic of China. Pilot Program for National Centralized Drug Procurement and Use; 2019. Available online: http://www.gov.cn/zhengce/content/2019-01/17/content_5358604.htm (accessed on January 9, 2021).

12. General Office of the State Council of the People's Republic of China. Opinions on promoting the normalization and institutionalization of centralized drug procurement; 2021. Available online: http://www.gov.cn/zhengce/content/2021-01/28/content_5583305.htm (accessed on March 25, 2021).

13. Shanghai Joint Procurement Office. Announcement of the results of the planned selection of centralized drug procurement in 4+7 cities; 2018. Available online: http://www.smpaa.cn/gjsdcg/2018/12/07/8531.shtml (accessed on December 25, 2020).

14. Hursh, S.; Bauman, R. The behavioral analysis of demand. In: Green L, Kagel J, ^editors. Advances in behavioral economics: Ablex, Norwood, NJ, 1987:117-65.

15. Hursh, SR. Behavioral economics of drug self-administration: an introduction. Drug and Alcohol Dependence 1993; 33:165-72. doi: https://doi.org/10.1016/0376-8716(93)90058-X.

16. Wang, H.; Li, X.; Chen, J. Impact of "4+7" City Drug Centralized Procurement Program on the utilization of original and generic cardiovascular drugs in a tertiary hospital. Journal of Pharmaceutical Practice 2020; 38:373-8. doi: 10.12206/j.issn.1006-0111.202001054.

17. Chen, L.; Yang, Y.; Luo, M.; Hu, B.; Yin, S.; Mao, Z. The Impacts of National Centralized Drug Procurement Policy on Drug Utilization and Drug Expenditures: The Case of Shenzhen, China. Int J Environ Res Public Health 2020; 17. doi: 10.3390/ijerph17249415.

18. Yang, Q.; Guo, W.; Liu, S. Effects of procuring with target quantity on using antipsychotics at a hospital. Chinese Journal of Hospital Pharmacy 2020:1-6. doi: 10.13286/j.1001-5213.2021.04.13.

19. Ye, S.; Kang, Q.; Gao, J.; Chen, Q.; Hu, S.; Cai, H.; Ding, R. Study of Drug Price Index in Evaluating Implementation Effect of "4+7" Drug Centralized Procurement Policy in Fujian. China Health Insurance 2020:35-9. doi: 10.19546/j.issn.1674-3830.2020.8.008.

20. Ma, F.; Wu, J. Methodological selection strategy analysis on medicine price index. Chinese Journal of Health Policy 2015; 8:61-7. doi: 10.3969/j.issn.1674-2982.2015.07.010.

21. Chen, B.; Hao, Y.; Dong, C.; Sun, L. A study on the application of drug price index in health insurance payment standard. Chinese Journal of Health Policy 2016; 9:38-42. doi: 10.3969/j.issn.1674-2982.2016.06.008.

22. Chen, W.; Cheng, X. Discussion on the methodology of drug price index. Chinese Health Economics 1995:29-31

23. WHO Collaborating Centre for Drug Statistics Methodology. Guidelines for ATC classification and DDD assignment 2021; 2021. Available online: http://www.whocc.no (accessed on March 6, 2021).

24. Jandoc, R.; Burden, AM.; Mamdani, M.; Lévesque, LE.; Cadarette, SM. Interrupted time series analysis in drug utilization research is increasing: systematic review and recommendations. Journal of Clinical Epidemiology 2015; 68:950-6. doi: 10.1016/j.jclinepi.2014.12.018. 
25. Lagarde, M. How to do (or not to do) ... Assessing the impact of a policy change with routine longitudinal data. Health Policy and Planning 2011; 27:76-83. doi: 10.1093/heapol/czr004.

26. Wagner, AK.; Soumerai, SB.; Zhang, F.; Ross-Degnan, D. Segmented regression analysis of interrupted time series studies in medication use research. J Clin Pharm Ther 2002; 27:299-309. doi: 10.1046/j.1365-2710.2002.00430.x.

27. Chang, F. Analysis on the core elements of centralized drug procurement. Chinese Health Resources 2021:1-5. doi: 10.13688/j.cnki.chr.2021.200774.

28. Tan, Q.; Yang, S.; Li, W.; Zhang, W. Effects, Key issues and Countermeasures of "4+7" Drug Volume-Based PurchasingPractice Based on Guangzhou. Health Economics Research 2020; 37:46-50. doi: 10.14055/j.cnki.33-1056/f.2020.04.027.

29. Tan, Z.; Fan, S. Challenges and Countermeasures of Pharmaceutical Enterprises under the Background of Centralized Purchasing of Drugs . Health Economics Research 2019; 36:13-5. doi: 10.14055/j.cnki.33-1056/f.2019.08.004.

30. Mao, Z.; Yang, Y.; Chen, L. Reform of Drug Supply and Guarantee System in China: Policy Measures and Effects. In: Wang C, Liang W, ^editors. Development Report on Health Reform in China (2020): Beijing: Social Sciences Academic Press, 2020:96-123.

31. Zhang, Y.; Wang, M. Analysis of the influence of " $4+7$ " on the use of ACEI antihypertensive drugs. Journal of Hunan Normal University(Medical Sciences) 2021; 18:189-92

32. Wang, Y.; Wu, Z. Keypoint Analysis of Monitoring Plan for Centralized Drug Purchase and Use Project Pilot Launched Organized by State. China Pharmacy 2019; 30:2317-22. doi: 10.6039/j.issn.1001-0408.2019.17.03. 